Albert P. Bos - Annemieke M. Pattenier

Rick E. Grobbee · Dick Lindhout · Dick Tibboel

Jan C. Molenaar

\title{
Etiological aspects of congenital diaphragmatic hernia: results of a case comparison study
}

Received: 3 January 1994 / Revised: 20 April 1994

\begin{abstract}
We report the results of a parental questionnaire concerning possible etiological and teratological factors, such as exposure to herbicides, in the development of congenital diaphragmatic hernia (CDH). The herbicide Nitrofen interferes with lung development in rats, can induce diaphragmatic hernia and greatly resembles thyroid hormone. No association with the studied teratogens nor with maternal thyroid dysfunction was found. The questionnaire was completed by 33 parents whose baby had $\mathrm{CDH}$, and by 43 couples whose baby had oesophageal atresia. The resemblance of Nitrofen to thyroid hormone, a well-known growth factor for the developing lung, is of particular interest from a pathogenetic point of view in the development of $\mathrm{CDH}$.
\end{abstract}

\section{Introduction}

Congenital diaphragmatic hernia $(\mathrm{CDH})$ is a serious malformation characterized by a diaphragmatic defect and bilateral lung hypoplasia (Areechon and Reid 1963). In the Netherlands its incidence is estimated at 1 in 3000 liveborns. Despite recent changes in therapeutic approach, its mortality rate still amounts to $40 \%$.

The etiology of $\mathrm{CDH}$ in the human newborn remains largely unknown (Cunnif et al. 1990), but in animal mod-

A. P. Bos $(\square)$ | · A. M. Pattenier - D. Tibboel · J. C. Molenaar Department of Pediatric Surgery,

Sophia Children's Hospital and Erasmus University Medical School, Rotterdam, The Netherlands

\section{R. E. Grobbee}

Department of Epidemiology and Biostatistics,

Sophia Children's Hospital and Erasmus University Medical School, Rotterdam, The Netherlands

D. Lindhout

Department of Clinical Genetics, Sophia Children's Hospital and Erasmus University Medical School, Rotterdam, The Netherlands

Present address: 'Sophia Hospital, Department of Pediatrics, P.O. Box 10400, NL-8000 GK Zwolle, The Netherlands els several teratological processes including exposure to chemicals have been found to induce $\mathrm{CDH}$ (Cullen et al. 1985). The present study was undertaken because within a few months five newborns from a circumscribed area with heavy industry and intensive agriculture and market gardening were admitted with $\mathrm{CDH}$. In these areas fertilizers and herbicides are extensively used.

In this study we report the results of a parental questionnaire concerning possible etiological and teratological factors in the development of $\mathrm{CDH}$.

\section{Patients and methods}

The Sophia Children's Hospital is a tertiary referral hospital that serves a region with a population of \pm 3 million inhabitants, and an annual birth rate of approximately 35000 newborns. We approached all parents of children with a posterolateral CDH $(n=48)$ admitted from 1985 to 1991; stillborns were excluded. Patients with an oesophageal atresia (EA) served as a control group $(n=$ 66). After giving their consent the parents received a questionnaire, consisting of 72 items. Questions were asked related to potential teratological data: marital status, family planning, contraception, treatment for delayed fertility, complications, illnesses and medications during gestation, way of delivery, occupation and social class, drug abuse alcohol abuse, smoking, X-rays, and exposure to occupational and environmental chemicals. Reference lists were included with the names of 42 commonly prescribed drugs and 40 chemicals (Addenda I and II). Statistical analysis was based on chi-square analysis of contingency tables. Statistical significance was accepted at the $P<0.05$ level.

\section{Results and discussion}

The final study group consisted of 33 couples (response rate $68 \%$ ) whose baby had $\mathrm{CDH}$, and 43 couples whose baby had EA (response rate 65\%). Mothers of newborns with EA showed a higher incidence of polyhydramnios and subsequently more ultrasound examinations, hospital admissions, and hospital deliveries. The incidence of ovulation induction procedures and spontaneous abortions in EA mothers was higher than in CDH mothers. The number of prescribed medications during pregnancy was higher in fathers and mothers (in the first month of pregnancy 
only) of CDH newborns. The type of drugs taken ranged widely and no specific association was found to be significant. The incidence of exposure to occupational and environmental chemicals did not differ between groups. Etiological studies in Hungary on isolated EA compared with normal controls also failed to show an association with studied teratogens (Szendrey et al. 1985).

The herbicide Nitrofen (2,4-dichlorophenyl-p-nitrophenyl ether) is an agent with a strong teratogenic potential that in rats interferes with lung development resulting in bilateral lung hypoplasia and induction of anatomical malformations including diaphragmatic hernias (Manson 1986). The stereochemical configuration of Nitrofen greatly resembles that of triiodothyronine $\left(\mathrm{T}_{3}\right)$ and thyroxine $\left(\mathrm{T}_{4}\right)$. Thyroid hormone is a well-known trophic factor for normal lung development and alveolar cell differentiation (DeMello et al. 1989). Moreover, maternal hypothyroidism has been associated with an increased risk of a variety of birth defects in offspring (Potter 1980; Khoury et al. 1989), but information on its role in $\mathrm{CDH}$ is lacking. The exact mechanism of teratogenesis is not known but evidence is accumulating that Nitrofen may interact with the embryonic nuclear receptors for thyroid hormone (Manson 1986).

This hypothesis links pulmonary hypoplasia and $\mathrm{CDH}$ with thyroid hormone status, and consequently, congenital defects with maternal thyroid disease. None of the mothers from either group suffered clinically from chronic thyroid dysfunction. These findings do not support the hypothesis that maternal hypothyroidism is a risk factor for the development of lung hypoplasia or $\mathrm{CDH}$. To enable further research into the etiology of $\mathrm{CDH}$, the actual moment of maldevelopment should be defined first: absent closure of the diaphragm and subsequent pulmonary hypoplasia, or an alternate pathogenetic mechanism with primary poor development of the lung bud and subsequent delay of closure of the pleuroperitoneal membrane, as has been suggested by Iritani (1984). The role of thyroid hormone status and that of thyroid hormone receptors in lung tissue and their relation with the development of lung hypoplasia in fetuses with $\mathrm{CDH}$ remains to be elucidated.

In conclusion, no etiological factors could be identified that are associated with either the development of $\mathrm{CDH}$ or EA. Although chemically induced birth defects account for only $5 \%$ of birth defects observed in the population (Wilson 1977), it remains worthwhile to identify potentially hazardous chemicals in the environment in order to minimize the risk of congenital malformations.

\section{References}

Areechon W, Reid L (1963) Hypoplasia of the lung with diaphragmatic hernia. BMJ 1:230-233
Cullen ML, Klein MD, Philippart AI (1985) Congenital diaphragmatic hernia. Surg Clin North Am 65:1115-1138

Cunnif C, Lyons Jones K, Jones MC (1990) Patterns of malformation in children with congenital diaphragmatic defects. J Pediatr 116:258-261

DeMello DE, Davies P, Reid LM (1989) Lung growth and development. Curr Pulmonol 10:159-208

Iritani I (1984) Experimental study on embryogenesis of congenital diaphragmatic hernia. Anat Embryol 169:133-139

Khoury MJ, Becerra JE, d'Almada PJ (1989) Maternal thyroid disease and risk of birth defects in offspring: a population-based case-control study. Paediatr Perinat Epidemiol 3:402-420

Manson JM (1986) Mechanism of Nitrofen teratogenesis. Environ Health Perspect $70: 137-147$

Potter JD (1980) Hypothyroidism and reproductive failure. Surv Gynecol Obstetr 150:251-255

Szendrey T, Danyi G, Czeizel A (1985) Etiological study on isolated esophageal atresia. Hum Genet 70:51-58

Wilson JG (1977) Teratogenic effects of environmental chemicals. Fed Proc 36: 1698-1703

\section{Addendum I}

\section{List of drugs}

Agiolax ${ }^{\mathbb{Q}}$, Semen Plantaginis Ovatae, Fructus Cassiae; Agrégola $^{\circledR}$, Cetylpyridinium Chloride; Algesal ${ }^{\text {(E) }}$, Diethylaminesalicylate; Antrenyl ${ }^{(\mathbb{(})}$, Oxyphenonium Bromide; APC ${ }^{(B)}$, Acetylsalicylic Acid, Caffeine, Paracetamol; Ascal ${ }^{\mathfrak{k}}$, Carbasalate Calcium; Augmentin $^{(3)}$, Amoxycillin, Clavulanic acid; Bactrimel ${ }^{(8)}$, Trimethoprim, Cotrimoxazole; Broxil ${ }^{(\hat{B})}$, Pheneticillin; Buscopan ${ }^{(i)}$, Hyoscine Butylbromide; Canesten ${ }^{\mathrm{E}}$, Clotrimazole; Clamoxyl ${ }^{\mathrm{k}}$, Amoxycillin: Coldrex ${ }^{1 \times}$, Acetylsalicylic acid, Phenylephrine; Daktarin ${ }^{16}$, Miconazole; Davitamon ${ }^{(\mathrm{B})}$, Vitamin A-B-E; Dolviran ${ }^{(\mathrm{T})}$, Acetylsalicylic Acid, Caffeine, Codeine; Dulcolax ${ }^{*}$, Bisacodyl; Duphalac ${ }^{(*)}$ Lactulose; Eryfer ${ }^{\mathbb{B}}$, Ferrous sulphate; Fero-Gradumet ${ }^{\overline{\mathbb{B}}}$, Ferrous sulphate; Ferumat ${ }^{\mathbb{E}}$. Ferrous fumarate; Finimal ${ }^{\mathbb{E}}$, Paracetamol, Caffeine; Flagyl ${ }^{\text {s. }}$. Metronidazole; Fortral ${ }^{2}$, Pentazocine; Gaviscon, Sodium alginate, Sodium hydrogenocarbonate: Glifanan ${ }^{(i)}$, Glafenine; Gynodaktarin ${ }^{(8)}$, Miconazole; Hedex ${ }^{(i)}$, Paracetamol; Metamucil $^{1 \times}$, Plantago ovata; Mogadon ${ }^{(1)}$. Nitrazepam; Nizoral ${ }^{\text {, }}$, Ketoconazole; Noctamid ${ }^{\text {(i) }}$, Lormetazepam; Normison ${ }^{(\hat{k})}$, Temazepam; Seresta $^{(2)}$. Oxazepam; Valdispert ${ }^{(2)}$. Valerian; Valium ${ }^{*}$, Diazepam

\section{Addendum II}

List of herbicides

Actor $^{\text {\$ }}$, Paraquat-diquat; Actril ${ }^{(B)}$, Ioxynil; A.U.MCPA ${ }^{2}$, MCPA; Baycor anti-yeast agent, Bitertanol; Birlane ${ }^{\text {t) }}$. Chlorfenvinphos; Bladafum ${ }^{\mathbb{B}}$, Sulfotep; Curator ${ }^{\mathbb{R}}$, Carbofuram; Dedevap ${ }^{\text {, }}$, Dichlorvos; Folimat ${ }^{\mathbb{B}}$, Omethoate; Gusadeen ${ }^{(k)}$, Azinphosmethyl/propoxur; Lannate $^{\left(\hat{B}_{3}\right.}$, Methomyl; Mesurol ${ }^{\text {a }}$, Methiocarb: Nitrofen ${ }^{2}$, Dinitrophenyl ether; Peropal ${ }^{(6)}$, Azocyclotin; Pirimor ${ }^{(*)}$, Pirimicarb; Ridomil ${ }^{\text {tiv }}$, Metalaxyl; Safrotin ${ }^{(\text {i }}$, Propetamphos; Tamaron ${ }^{(i)}$, Methamidophos: Telone $^{(i)}$, 1,3-dichlorpropene; Thiovit ${ }^{(\mathbb{1})}$, Sulphur; TMTD ${ }^{(\mathbb{B})}$, Thiram: Topsin $^{(k)}$, Thiophanate-methyl; Torque ${ }^{(k)}$, Fenbutatinoxide; Trimaton $^{(3)}$, Metamsodium; Vitigran ${ }^{(i)}$, Copperoxychloride; Dinoseb; Zineb; Formothion; Endosulfan; Phosphamidon; Zineb 